\title{
RESEARCH
}

Open Access

\section{Soluble fibrinogen-like protein 2 promotes the growth of hepatocellular carcinoma via attenuating dendritic cell-mediated cytotoxic $\mathrm{T}$ cell activity}

Muyang Yang ${ }^{1}$, Zhongwei Zhang ${ }^{1}$, Jiajia Chen ${ }^{1}$, Mengying $X u^{1}$, Jiaquan Huang ${ }^{1,2}$, Ming Wang ${ }^{1,2}$, Weina $\mathrm{Li}^{1,2}$, Xiaoyang Wan ${ }^{1}$, Man-Fung Yuen ${ }^{3}$, Xiaoping Luo ${ }^{4}$, Dong $\mathrm{Xi}^{i^{*}}$ and Qin Ning ${ }^{1,2^{*}}$ (D)

\begin{abstract}
Background: Soluble fibrinogen-like protein 2 (sFGL2), a secretory protein expressed by regulatory $T$ cells (Tregs) with immunosuppressive activity, is highly expressed in both the peripheral blood and tumor tissue of patients with hepatocellular carcinoma (HCC); however, sFGL2 function in HCC remains largely unknown. Here, we elucidated the potential role of sFGL2 in HCC progression.

Methods: T cells, dendritic cells (DCs), and related cytokines in the tumor microenvironment were comparatively analyzed in BALB/C and C57BL/6 mice bearing transplanted hepatomas harboring Fg/2-knockout or receiving sFGL2antibody treatment. Additionally, the effects of sFGL2 on DCs and T cells were evaluated in vivo and ex vivo.

Results: The growth of both subcutaneously and orthotopically transplanted hepatomas was inhibited in Fgl2knockout mice and those treated with the sFGL2 antibody, respectively, as compared with controls. Moreover, sFGL2 depletion enhanced the proportion and cytotoxicity of cytotoxic T cells, promoted DC maturation, and improved DC activity to proliferate T cells in the tumor microenvironment. Furthermore, we detected lower levels of interleukin (IL)-35 in both types of transplanted hepatomas and higher level of IL-6 in orthotopically transplanted hepatomas following sFGL2 depletion. Mechanistically, we found that sFGL2 impaired bonemarrow-derived DC (BMDCs) function by inhibiting phosphorylation of Akt, nuclear factor-kappaB, CAMP response element binding protein, and p38 and downregulating the expression of major histocompatibility complex II, CD40, CD80, CD86, and CD83 on BMDCs in vitro.
\end{abstract}

Conclusions: Our data suggest that sFGL2 promotes hepatoma growth by attenuating DC activity and subsequent $\mathrm{CD}^{+} \mathrm{T}$ cell cytotoxicity, suggesting SFGL2 as a novel potential therapeutic target for HCC treatment.

Keywords: Soluble fibrinogen-like protein 2, Hepatocellular carcinoma, Tumor microenvironment, Dendritic cells, Immunosuppression

\footnotetext{
*Correspondence: xidong@tjh.tjmu.edu.cn; qning@vip.sina.com

'Institute of Infectious Disease, Tongji Hospital of Tongji Medical College,

Huazhong University of Science and Technology, Wuhan 430030, China

Full list of author information is available at the end of the article
}

(c) The Author(s). 2019 Open Access This article is distributed under the terms of the Creative Commons Attribution 4.0 International License (http://creativecommons.org/licenses/by/4.0/), which permits unrestricted use, distribution, and reproduction in any medium, provided you give appropriate credit to the original author(s) and the source, provide a link to the Creative Commons license, and indicate if changes were made. The Creative Commons Public Domain Dedication waiver (http://creativecommons.org/publicdomain/zero/1.0/) applies to the data made available in this article, unless otherwise stated. 


\section{Background}

Hepatocellular carcinoma (HCC), the second leading cause of cancerous mortality, is associated with hepatitis B or $\mathrm{C}$ virus infection, which otherwise induces immune tolerance $[1,2]$. Resistance to HCC treatment is widely attributed to immune-regulatory cells, such as regulatory $\mathrm{T}$ cells (Tregs), myeloid-derived suppressor cells (MDSCs), and tumor-associated macrophages (TAMs) in the tumor microenvironment [3]. Interleukin (IL)-10 and transforming growth factor (TGF)- $\beta$, immunosuppressive cytokines secreted mainly by Tregs, are commonly detected in the serum of HCC patients in many cases, with both cytokines capable of inhibiting immune surveillance and protecting tumor growth by attenuating $T$ cell activation $[4,5]$. Additionally, immune checkpoint proteins, including cytotoxic T-lymphocyte-associated antigen 4 (CTLA-4), programmed cell death 1 (PD-1), and programmed cell death-ligand 1 (PD-L1), are expressed on Tregs, TAMs, MDSCs, and hepatoma cells and inhibit activation of effector immune cells, such as cytotoxic T cells (CTLs) and natural killer (NK) cells, in tumor tissue [6]. Although attempts have been made to treat $\mathrm{HCC}$ with immunecheckpoint inhibitors, efficiency varies in individuals, which limits their use $[7,8]$. Therefore, it is important to elucidate an expanded spectrum of immune regulators in the tumor microenvironment in order to identify potential therapeutic targets.

Fibrinogen-like protein 2 (FGL2)/fibroleukin is a member of the fibrinogen-related protein superfamily and comprises both membrane and soluble subtypes [9]. Soluble FGL2 (sFGL2) is an immunosuppressive factor that inhibits dendritic cells (DCs) [10] by binding to the FcyRIIB receptor [11]. As an immune regulator, sFGL2 plays a critical role in the immune balance in autoimmune diseases and can restrict the progression of autoimmune glomerulonephritis [12] and T cell-induced colitis [13]. However, in viral hepatitis, sFGL2 attenuates antiviral immunity, leading to poor prognosis, with impaired Treg function and prolonged survival time observed following FGL2 blockage in murine models of viral fulminant hepatitis [14]. Another study showed that sFGL2 depletion inhibits glioma growth and decreases the numbers of MDSCs, alternatively activated macrophages (M2 macrophages), and CD39+ Tregs [15]. Additionally, sFGL2 promotes the accumulation of MDSCs via $\mathrm{C}-\mathrm{X}-\mathrm{C}$ motif chemokine ligand 12 and increases the number of activated cancer-associated fibroblasts in a murine model of lung cancer [16]. In an HCC study, levels of serum sFGL2 were reportedly higher in HCC patients [17], and hepatic stellate cells were found to secrete sFGL2 and inhibit the proliferation of $\mathrm{CD}^{+} \mathrm{T}$ cells, thereby hindering antitumor immunity [18]. However, the function of sFGL2 in $\mathrm{HCC}$ remains largely unknown.
In this study, we established transplanted hepatoma models and investigated the role of sFGL2 in HCC growth. Our data showed that sFGL2 blockage by antibody interference or genetic deletion decreased hepatoma burden by enhancing DC activation and increasing CTL number and cytotoxicity in tumor tissue while having minimal effect on MDSC and M2 macrophage numbers. Mechanistically, we found that sFGL2 hindered the expression of major histocompatibility complex II (MHCII), CD40, CD80, CD86, and CD83 and attenuated the phosphorylation of Akt, nuclear factor-kappaB (NF$\kappa \mathrm{B})$, cAMP response element binding protein (CREB), and p38 on bone marrow-derived DCs (BMDCs) in vitro, which influenced DC activation.

\section{Methods \\ Animals}

Female wide-type (WT) BALB/c and C57BL/6 mice (aged 6-8 weeks) were purchased from Beijing Vital River Laboratory Animal Technology Co., Ltd. (Beijing, China). Syngeneic $\mathrm{Fgl2}^{-/-}$mice were generated by the Beijing Genomics Institute (Beijing, China). All mice were kept in micro-isolator cages, and the experimental protocols were approved by the Animal Ethics Committee.

\section{HCC models}

BNL 1ME A.7R.1 cells (BNL cells; $8 \times 10^{6}$ ) and Hepa1-6 cells $\left(8 \times 10^{6}\right)$ were respectively transplanted into the left flank of BALB/c and C57BL/6 mice to create subcutaneous HCC models. BNL cells are a liver epithelial cell line from $\mathrm{BALB} / \mathrm{c}$ mice that exhibit malignant properties. Hepa1-6 cells are derived from hepatomas from BW7756 mice and arise in C57BL/6 mice. Tumor volumes were measured every 2 days, and $100 \mu \mathrm{g}$ of the FGL2 antibody or isotype were injected intratumorally twice weekly once the tumor volume reached $>100$ $\mathrm{mm}^{3}$. In a separate experiment, the same number of liver cancer cells was inoculated into the left flank of WT and syngeneic $\mathrm{Fgl2}^{-/-}$mice. Additionally, to explore the effect of IL-35 on the hepatoma environment, $100 \mu \mathrm{g}$ IL-35 antibody or isotype (Abcam, Cambridge, UK) were injected intra-tumorally once weekly when the tumor volume reached $>100 \mathrm{~mm}^{3}$. To establish an orthotopically transplanted HCC model, $1 \times 10^{6} \mathrm{BNL}$ cells were implanted into the left lateral liver lobes of WT and syngeneic $\mathrm{Fgl2}^{-/-} \mathrm{BALB} / \mathrm{c}$ mice.

\section{Anti-FGL2 polyclonal antibody}

For treatment of hepatoma-burdened mice, we used a rabbit polyclonal antibody against a partial form of FGL2 (amino acids 338-356) that included the fibrinogen-related domain critical for immunosuppressive function [19]. The preparation, purification, and 
identification of the antibody were completed by the Proteintech Group Inc. (Rosemont, IL, USA), which also provided the isotype IgG antibody.

\section{Cell culture}

BNL and Hepa1-6 cells were cultured in Dulbecco's minimum essential medium containing $10 \%(\mathrm{v} / \mathrm{v})$ fetal bovine serum (Gibco, Gaithersburg, MD, USA) and $100 \mu \mathrm{g} / \mathrm{mL}$ penicillin/streptomycin (Invitrogen, Carlsbad, CA, USA). In the logarithmic growth phase, cells were harvested and implanted into mice subcutaneously or orthotopically.

Magnetic cell isolation and cell separation (MACS; Miltenyi Biotec, Bergisch Gladbach, Germany) was used to isolate $\mathrm{CD} 4^{+} \mathrm{CD} 25^{-}$and $\mathrm{CD} 8^{+} \mathrm{T}$ cells from tumor tissue of untreated WT mice. Subsequently, these cells were mixed with DCs from tumors derived from different groups at various proportions. T cells were dyed with $5 \mu \mathrm{M}$ carboxyfluorescein succinimidyl amino ester (CFSE) prior to 3-day culture in the presence of $200 \mathrm{IU} /$ $\mathrm{mL}$ murine IL-2 (PeproTech, Rocky Hill, NJ, USA) in 96-well round-bottomed plates for $72 \mathrm{~h}$. The proliferated $\mathrm{T}$ cells were detected according to the percentage of CFSE dilution. For $\mathrm{T}$ helper (Th) cell-differentiation analysis, $\mathrm{CD} 4^{+} \mathrm{CD} 25^{-} \mathrm{T}$ cells were mixed with $\mathrm{DCs}$ from tumors at a 5:1 ratio and cultured in the presence of 200 $\mathrm{IU} / \mathrm{mL}$ murine IL-2 in 96-well round-bottomed plates for 6 days. Th1 and Th2 cells and Tregs were measured and respectively characterized as interferon (IFN) $-\gamma^{+}$, IL$4^{+}$, and $\mathrm{CD} 25^{+}$forkhead box $\mathrm{P}^{+}\left(\mathrm{Foxp}^{+}\right)$cells among $\mathrm{CD} 4^{+} \mathrm{T}$ cells.

To analyze $\mathrm{CD}^{+} \mathrm{T}$ cell cytotoxicity in tumors, $10^{4}$ ultraviolet inactivated BNL cells were mixed with $10^{5}$ $\mathrm{CD}^{+} \mathrm{T}$ cells for $72 \mathrm{~h}$. Subsequently, the $\mathrm{CD}^{+} \mathrm{T}$ cells were mixed with $10^{4}$ BNL cells in the logarithmic growth phase for $12 \mathrm{~h}$ in order to detect BNL cell apoptosis by 7 -aminoactinomycin D (7-AAD) staining.

To obtain BMDCs, bone-marrow cells were separated from mouse tibias, and immature BMDCs were harvested after 6 days of culture with $10 \mathrm{ng} / \mathrm{mL} \mathrm{IL-4}$ and 10 $\mathrm{ng} / \mathrm{mL}$ granulocyte macrophage-colony stimulating factor (GM-CSF; PeproTech).

\section{Cytokine analysis}

IL-12p70, IL-35, and TGF- $\beta$ in the homogenate were detected using enzyme-linked immunosorbent assay (ELISA) kits (Biolegend, San Diego, CA, USA) at an absorbance of $540 \mathrm{~nm}$. Cytometric bead array (CBA; BD Biosciences, San Diego, CA, USA) was used to measure IL-4, IL-6, IL-10, TNF- $\alpha$, and IFN- $\gamma$ levels.

\section{Flow cytometric analysis}

Cell phenotype was assessed by flow cytometry (BD LSRFortessa; BD Biosciences) after incubation with the following fluorescein-labeled antibodies: CD45-allophycocyanin (APC)-eFluor780, CD3e-fluorescein isothiocyanate (FITC), CD4-APC, CD8a-phycoerythrin (PE)-cy7, CD25PE-cy7, Foxp3-PE, IFN- $\gamma$-AlexaFluor488, IL-4-PE-cy7, CD107a-PE, granzymeB-peridinin chlorophyll (PerCP)eFluor710, perforin-FITC, CD11c-PE-cy7, CD80-PerCPeFluor710, CD83-FITC, B7-H4-PE, and CD31-PE. All antibodies were purchased from eBioscience (San Diego, CA, USA), except CD4-APC, CD8a-PE-cy7, and Foxp3-PE (BD Biosciences). Intracellular antigens were determined after incubation with ionomycin $(500 \mathrm{ng} / \mathrm{mL}$; Abcam, Cambridge, UK) and phorbol-12-myristate13-acetate $(10 \mathrm{ng} / \mathrm{mL}$; Sigma-Aldrich, St. Louis, MO, USA) for $1 \mathrm{~h}$ and monensin ( $2 \mu \mathrm{M}$; eBioscience) for an additional $4 \mathrm{~h}$. Fixation and permeabilization were performed prior to antibody incubation, and data were analyzed using FlowJo software (TreeStar, Ashland, OR, USA).

\section{Analysis of DC surface markers and cell-signaling pathways in vitro}

BMDCs were incubated with $4 \mu \mathrm{g} / \mathrm{mL}$ recombinant murine FGL2 (R\&D Systems, Minneapolis, MN, USA) for $16 \mathrm{~h}$ and stimulated with $500 \mathrm{ng} / \mathrm{mL}$ lipopolysaccharide (LPS; Sigma-Aldrich) for $12 \mathrm{~h}$. BMDCs were then harvested, and the expression of MHCII, CD40, CD80, CD86, and CD83 was assessed by flow cytometry. To analyze cell-signaling pathways, BMDCs were treated with recombinant murine FGL2 $(0,0.5,1$, or $2 \mu \mathrm{g} / \mathrm{mL})$ for $16 \mathrm{~h}$, followed by $500 \mathrm{ng} / \mathrm{mL}$ LPS stimulation for $30 \mathrm{~min}$. Relevant proteins in cells were extracted and their concentrations measured using a standard bicinchoninic acid assay (Pierce Biotechnology, Rockford, IL, USA). After sodium dodecyl sulfate polyacrylamide gel electrophoresis (SDS-PAGE) and transfer to polyvinylidene fluoride membranes for western blot, 5\% not-fat milk was used for blocking for $1 \mathrm{~h}$ at room temperature. Primary antibodies were incubated with membranes at $4{ }^{\circ} \mathrm{C}$ overnight. Following several wash steps with Tris-buffered saline with Tween-20 (TBST), secondary antibodies were incubated for $1 \mathrm{~h}$ at room temperature. Proteins were detected using enhanced chemiluminescence reagent (Servicebio, Wuhan, China), and the integrated optical density (IOD) of the proteins was calculated using a Gel-pro analyzer (Media Cybernetics, Rockville, MD, USA). Antibodies against Akt, phosphorylated (p)-Akt, mechanistic target of rapamycin (mTOR), p-mTOR, NF-kB-p65, pNF-kB-p65, CREB, p-CREB, p38, p-p38, Erk1/2, and p-Erk1/2 were obtained from Cell Signaling Technology (Danvers, MA, USA), and antibodies for glyceraldehyde 3-phosphate dehydrogenase and histone-3 were purchased from Servicebio. 
a

\section{BNL cells inoculated into BALB/c mice}

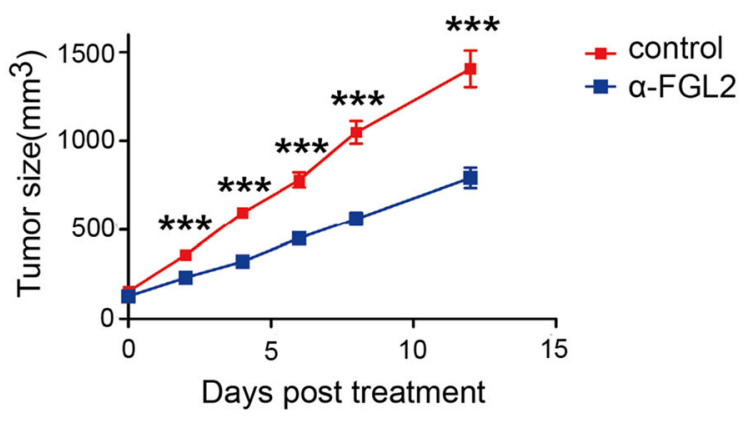

control

$\alpha-F G L 2$

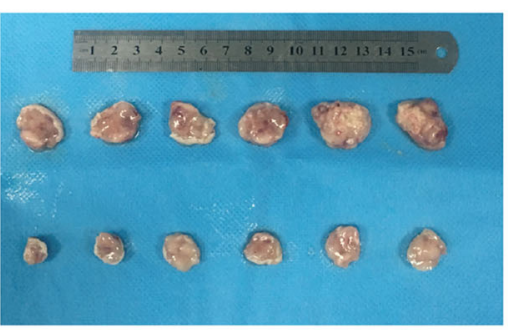

b

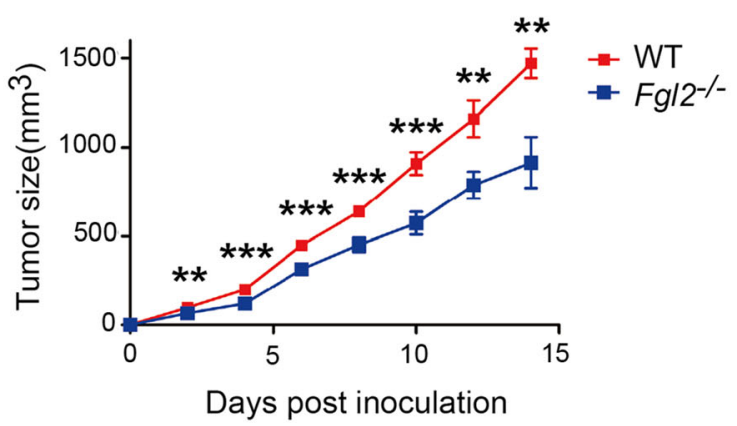

WT

$\mathrm{Fg} / 2^{-/-}$

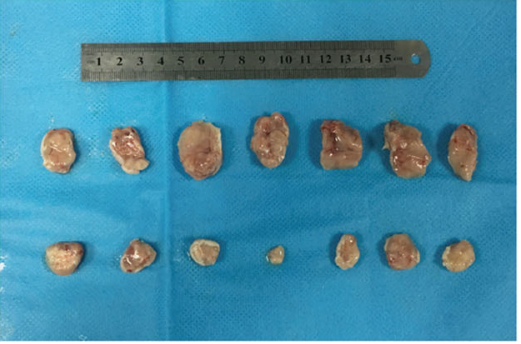

\section{Hepa1-6 cells inoculated into C57BL/6 mice}

C
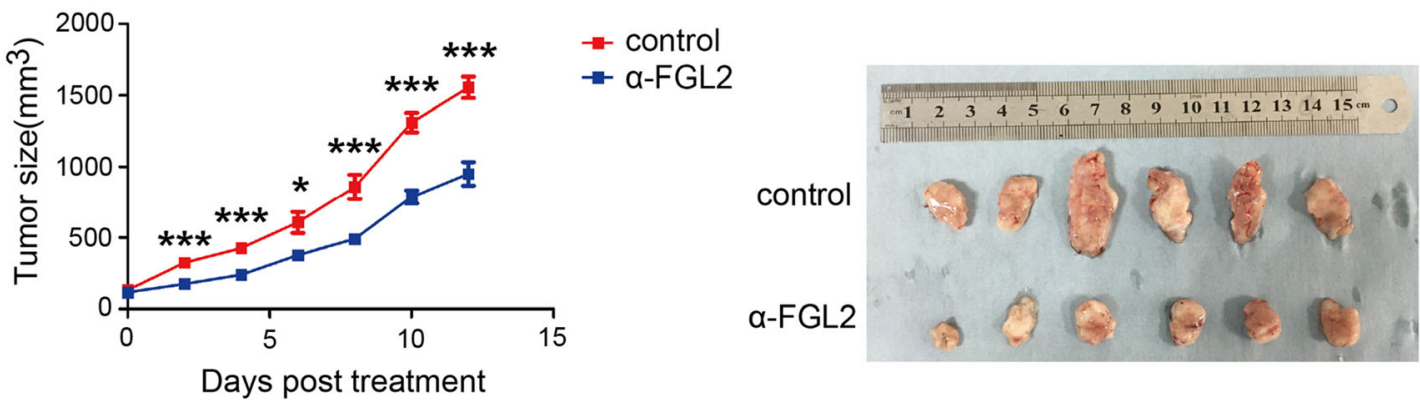

d

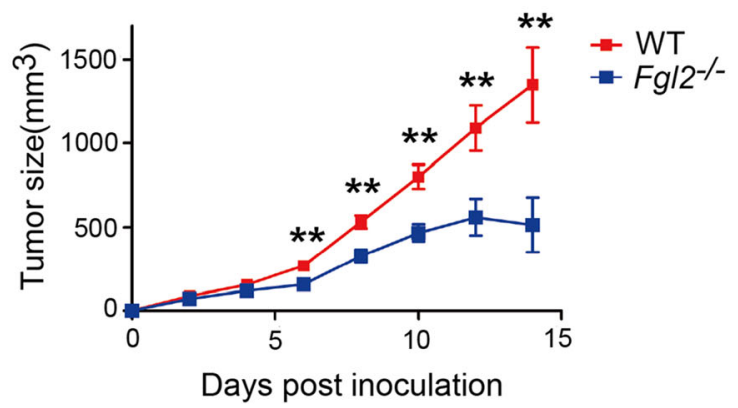

WT

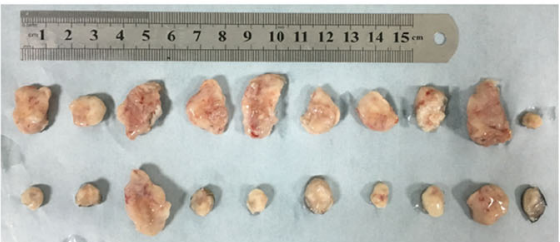

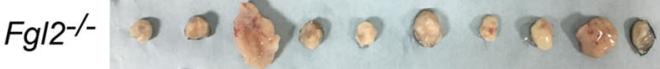

Fig. 1 (See legend on next page.) 
(See figure on previous page.)

Fig. 1 FGL2-antibody treatment or Fgl2 knockout inhibits the growth of subcutaneously (s.c.) transplanted murine hepatoma. a BNL cells $\left(8 \times 10^{6}\right)$ were inoculated s.c. into BALB/c mice, and c C57BL/6 mice were injected s.c. with $8 \times 10^{6}$ Hepa1-6 cells. In the anit-FGL2 group, mice were injected with $100 \mu \mathrm{g}$ anti-FGL2 (a-FGL2) or isotype dissolved in $100 \mu \mathrm{L}$ phosphate-buffered saline every 3 days after the tumor size exceeded 100 $\mathrm{mm}^{3}$. Tumor volumes were measured every 2 days. b BNL cells $\left(8 \times 10^{6}\right)$ were inoculated s.c. into $\mathrm{Fg} / 2^{-1-}$ or WT BALB/c mice, and $\mathbf{d} \mathrm{Fg} / 2^{-/-}$and WT C57BL/6 mice were injected s.c. with $8 \times 10^{6} \mathrm{Hepa} 1-6$ cells. Tumor volumes were measured every 2 days. ${ }^{*} P<0.05,{ }^{* *} P<0.01,{ }^{* * *} P<0.001$ (two-tailed unpaired Student's $t$ test) as compared with the control

\section{Statistical analysis}

Data were expressed as mean \pm SEM unless otherwise specified. Significance between groups of absolute values was determined by Student's $t$ test, and the Mann-Whitney $U$ test was used to analyze percentages. The logrank test was used to compare survival rates between groups. A $P<0.05$ was considered significant.

\section{Results}

FGL2-antibody treatment or Fgl2 knockout inhibits tumor growth in subcutaneously transplanted HCC models

To investigate the role of sFGL2 in HCC progression, the growth of BNL or Hepa1-6 cells was evaluated in subcutaneous murine $\mathrm{HCC}$ models in $\mathrm{Fgl}^{-1-}$ mice or treated with the anti-FGL2 antibody in WT mice with a $\mathrm{BALB} / \mathrm{c}$ or $\mathrm{C} 57 \mathrm{BL} / 6$ background. The results showed that FGL2 blockage using the anti-FGL2 antibody (Fig. 1a) or Fgl2 knockout (Fig. 1b) reduced BNL cell growth in BALB/c mice. Similarly, tumor sizes in C57BL/6 mice bearing Hepa1-6 cells were significantly smaller in groups receiving anti-FGL2 treatment (Fig. 1c) or harboring the Fgl2 knockout (Fig. 1d) as compared with controls. These data indicated the involvement of sFGL2 in hepatoma progression, and that blockage of sFGL2 represents a potentially novel HCC therapy.

sFGL2 blockage reduces IL-35 levels, elevates the number of tumor-infiltrated $\mathrm{CD}^{+} \mathrm{T}$ cells with enhanced cytotoxicity, and promotes DC maturation in subcutaneously transplanted HCC models

We screened for typical cytokines in tumor homogenates at 2-weeks post-inoculation of BALB/c mice with BNL cells. We found barely detectable levels of sFGL2 in tumor homogenate from $\mathrm{Fgl2}^{-/-}$mice (Additional file 1: Figure S1a). IL-35 derived from Tregs is a critical immunomodulatory cytokine that inhibits $\mathrm{T}$ cell activity and promotes tumor growth. We found significantly lower IL-35 levels in tumor homogenate from $\mathrm{Fgl2}^{-1-}$ mice relative to that from WT mice $(2637 \pm 383.7 \mathrm{pg} / \mathrm{mL}$ vs. $4938 \pm 1348 \mathrm{pg} / \mathrm{mL}$; $P<0.05)$ (Fig. 2a). To investigate the immunological mechanism associated with sFGL2-mediated tumor promotion, tumor tissues and draining lymph nodes (DLNs) were dissected and prepared as single-cell suspensions in order to examine immunological features. Measurement of $\mathrm{CD}^{+}, \mathrm{CD}^{+}$, and $\mathrm{CD}^{+} \mathrm{T}$ cells and DCs by flow cytometric analysis indicated elevated levels of $\mathrm{CD}^{+} \mathrm{T}$ cells (Fig. 2b) and Th1 cells (IFN- $\gamma^{+} \mathrm{CD}^{+} \mathrm{T}$ cells) (Fig. 2c) in DLNs. Additionally, we observed a $61.3 \%$ reduction in Treg percentage among $\mathrm{CD}^{+} \mathrm{T}$ cells in BNL-derived tumor tissue from $\mathrm{Fgl2}^{-/-}$mice (Fig. 2c). Tumor-infiltrated CD8 lymphocytes are the primary sources of antitumor immunity, with their activation characterized by presentation of CD107a and the production of granzyme B and perforin, which kill tumor cells. Here, we found a 2.52-fold increase of $\mathrm{CD}^{+} \mathrm{T}$ cells and significantly higher expression of CD107a and production of granzyme $\mathrm{B}$ and perforin in tumors from $\mathrm{Fgl2}^{-/-}$mice, with similar results observed in DLNs (Fig. 2d). To determine the enhanced cytotoxicity of tumor-infiltrated $\mathrm{CD}^{+} \mathrm{T}$ cells, the cells were isolated from tumors by MACS and mixed with BNL cells following stimulation with inactivated BNL cells. We observed 1.83-fold increase in the percentage of BNL cells undergoing apoptosis following incubation with $\mathrm{CD}^{+} \mathrm{T}$ cells derived from $\mathrm{Fgl2}^{-/-}$ mice, indicating the augmented cytotoxicity of the tumor-infiltrated $\mathrm{CD}^{+} \mathrm{T}$ cells (Fig. 2e).

Previous studies demonstrated that sFGL2 hinders DC maturation and function in vitro [10]. To explore whether sFGL2 hampers DCs during HCC progression, we analyzed DCs from the tumors and DLNs of mice subcutaneously transplanted with HCC (Fig. 2f). The proportion of $\mathrm{CD} 31^{+} \mathrm{DCs}$ decreased significantly in the tumor, whereas the number of $\mathrm{MHCII}^{+} \mathrm{DCs}$ increased in DLNs from $\mathrm{Fgl2}^{-/-}$mice. Moreover, analysis of the number of MDSCs and M2 macrophages in tumors and DLNs revealed similar levels between $\mathrm{Fgl2}^{-/-}$and WT mice (Additional file 1: Figure S2a).

We then evaluated the numbers of T cells and DCs in Hepa1-6-derived tumors in C57BL/6 mice, finding a larger number of $\mathrm{CD}^{+} \mathrm{T}$ cells in tumors (Additional file 1: Figure S3a) and Th1 cells in tumors and DLNs (Additional file 1: Figure S3b) in $\mathrm{Fgl2}^{-/-}$mice. Additionally, analysis of $\mathrm{CD}^{+} \mathrm{T}$ cells revealed that Fgl2 knockout elevated the number of tumor-infiltrated $\mathrm{CD}^{+} \mathrm{T}$ cells and their production of granzyme B in DLNs (Additional file 1: Figure S3c). Moreover, we observed elevated expression of CD83 on DCs in Fgl2 ${ }^{-1-}$ mice. Furthermore, 


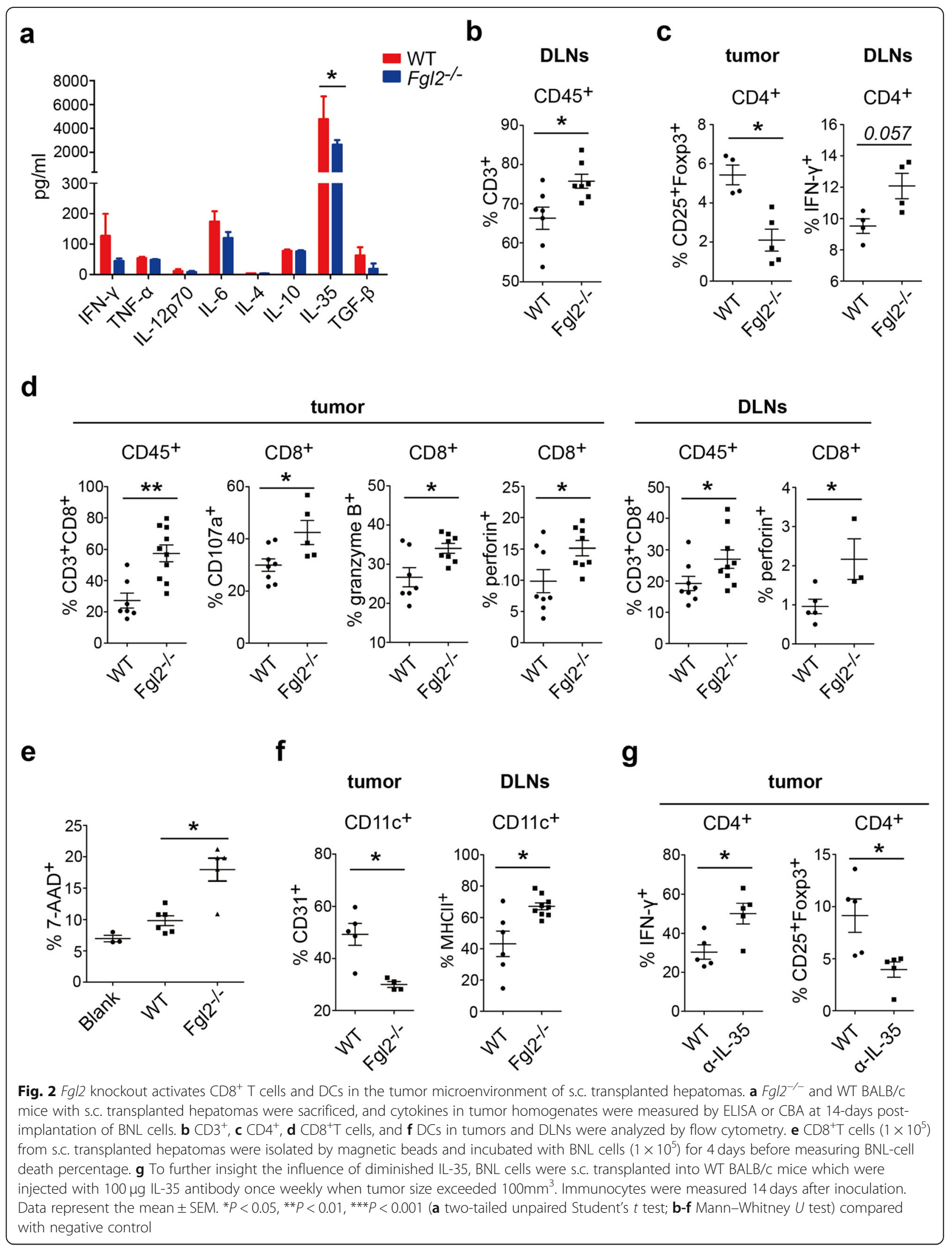


a

\section{$\mathrm{DC}: \mathrm{CD}^{+}{ }^{+} \mathrm{CD} 25^{-} \mathrm{T}$ cells}

$0: 1$

$1: 2$

$1: 5$

$1: 10$

$1: 50$
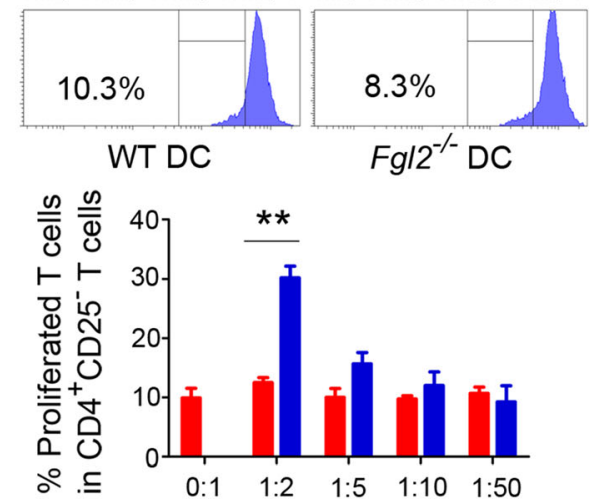

$16.3 \%$
DC:CD8 ${ }^{+} T$ cells

$0: 1$

$12.1 \%$

$1: 2$

$1: 5$

$1: 10$

$1: 50$

$11.9 \% \quad 10.7 \%$

WT DC

$\mathrm{Fg} / 2^{-/-} \mathrm{DC}$

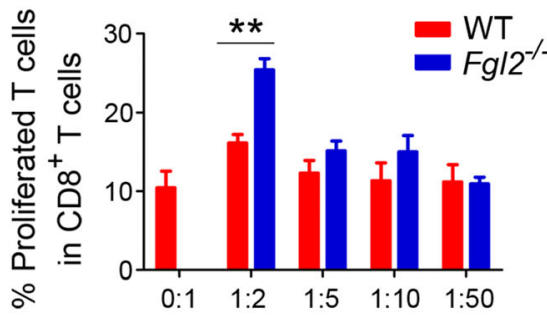

b

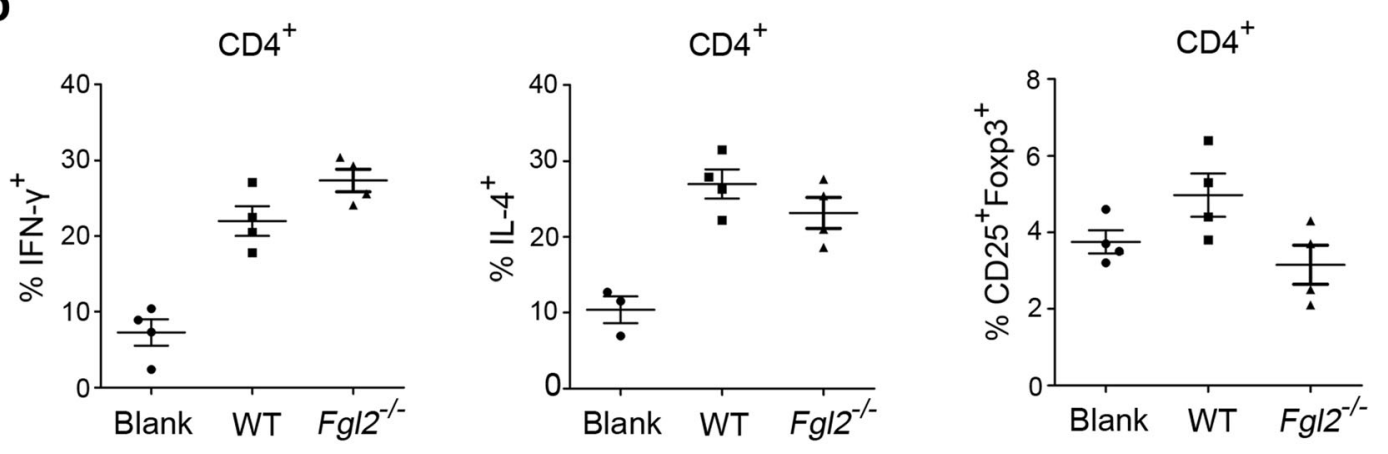

C
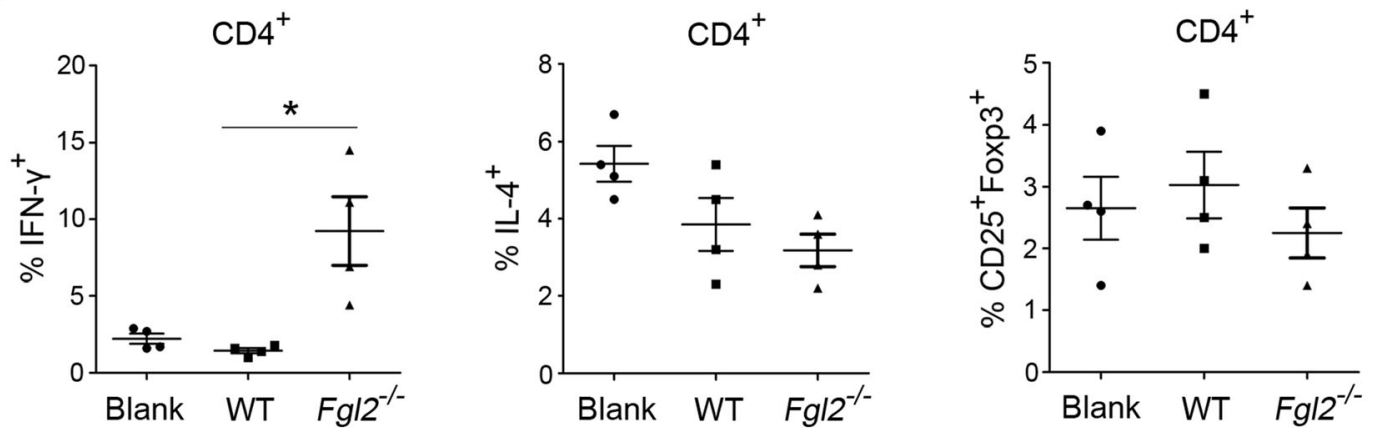

Fig. 3 (See legend on next page.) 
(See figure on previous page.)

Fig. $3 \mathrm{Fg} / 2$ knockout promotes DC-mediated T cell proliferation in s.c. transplanted hepatomas. $C D 4^{+} C D 25^{-}$and $C D 8^{+}$T cells and DCs were isolated from s.c. transplanted hepatoma tissue from Fg/2 ${ }^{-1-}$ or WT BALB/C mice using magnetic beads. T cells $\left(1 \times 10^{5}\right)$ were dyed with CFSE $(5 \mu \mathrm{M})$ and mixed with DCs at different ratios (DC:T cells, 1:2, 1:5, 1:10, and 1:50) in the presence of $200 \mathrm{IU} / \mathrm{mL}$ murine IL-2 in culture. a T cell proliferation was measured after incubation for $72 \mathrm{~h}$ in 96 -well round-bottomed plates. $\mathbf{b}$ at a DC:T ratio of 1:2, the percentages of CD4 ${ }^{+}$IFN- $\gamma^{+} \mathrm{T}$ cells (Th1), CD4 ${ }^{+} \mathrm{IL}-4^{+} \mathrm{T}$ cells (Th2), and $\mathrm{CD} 4^{+} \mathrm{CD} 25^{+} \mathrm{Foxp}^{+} \mathrm{T}$ cells (Tregs) among CD4 ${ }^{+} \mathrm{CD} 25^{-} \mathrm{T}$ cells were quantified after incubation for 6 days. $\mathbf{c}$ $\mathrm{CD}^{+} \mathrm{CD} 25^{-}, \mathrm{CD} 8^{+} \mathrm{T}$ cells, and DCs were isolated from s.c. transplanted hepatoma tissue from WT BALB/c mice in the presence or absence of treatment with anti-FGL2. The percentages of Th1 and Th2 cells and Tregs among CD4 ${ }^{+} \mathrm{CD} 25^{-} \mathrm{T}$ cells were measured as described in (b). Data represent the percentage of positive cells (mean \pm SEM). ${ }^{*} P<0.05$, ${ }^{*} P<0.01$ (Mann-Whitney $U$ test) as compared with the negative

control group

analysis of the immunological features of $\mathrm{T}$ cells and DCs in tumors from BALB/c (Additional file 1: Figure S4) and C57BL/6 (Additional file 1: Figure S5) mice following anti-FGL2 treatment showed similar results. These data suggested that sFGL2 impaired antitumor immunocytes in the hepatoma microenvironment.

Our results showed IL-35 levels was much lower in tumor from $\mathrm{Fgl2}^{-/-}$mice. To further explore the influence of diminished IL-35, $8 \times 10^{6}$ BNL cells were s.c. injected into BALB/c mice, then $100 \mu \mathrm{g}$ IL35 antibody were injected intra-tumorally once weekly when the tumor volume reached $>100 \mathrm{~mm}^{3}$. Immunocytes were examined 14 days after tumor inoculation and we found significantly more Th1 cells and fewer Tregs in tumor from anti-IL-35 treatment group compared with control (Fig. 2g).

sFGL2 blockage promotes DC stimulation of T cells in the tumors of subcutaneously transplanted HCC models

Because variations in the expression of DC-surface molecules do not guarantee changes in DC function, we performed an ex vivo mixed-lymphocyte culture assay. DCs, $\mathrm{CD} 4^{+} \mathrm{CD} 25^{-}$effector Th cells, and $\mathrm{CD} 8^{+} \mathrm{T}$ cells from subcutaneously transplanted tumors were isolated by MACS prior to mixing the DCs with different ratios of $\mathrm{T}$ cells. The results demonstrated that DCs from mice treated with antiFGL2 (Additional file 1: Figure S6) or $\mathrm{Fgl2}^{-/-}$mice (Fig. 3a) displayed an enhance ability to promote both $\mathrm{CD} 4^{+} \mathrm{CD} 25^{-}$ $\mathrm{T}$ and $\mathrm{CD}^{+} \mathrm{T}$ cell proliferation at a DC: $\mathrm{T}$ cell ratio of 1:2. $\mathrm{CD} 4{ }^{+} \mathrm{CD} 25^{-}$effector Th cells and DCs were subsequently mixed and cultured for 6 days, revealing that the percentages of Th2 cells and Tregs among $\mathrm{CD}^{+} \mathrm{T}$ cells were not altered by sFGL2 blockage (Fig. 3b and c); however, we observed a significantly greater number of Th1 cells in mice treated with anti-FGL2 as compared with controls (Fig. 3c). These data indicated that sFGL2 depletion enhanced DC function associated with mediation of $\mathrm{T}$ cell activation.

\section{Fgl2 knockout suppresses the growth of orthotopically transplanted hepatoma and activates tumor-infiltrated CD8 lymphocytes and DCs}

Because the subcutaneously implanted hepatoma model is not a perfect analogue of HCC in the liver, an orthotopically transplanted HCC model was developed for further verification. Briefly, $1 \times 10^{6} \mathrm{BNL}$ cells were implanted into liver lobes of $\mathrm{Fgl2}^{-/-}$or WT BALB/c mice, after which all 15 WT mice died, and five of the $15 \mathrm{Fgl2}^{-/-}$mice survived 40 days after tumor inoculation (Fig. 4a). Tumors were isolated following sacrifice of mice at 14-days post-transplantation from another groups of mice with tumor burden, revealing lower IL$35(560.7 \pm 264.0 \mathrm{pg} / \mathrm{mL}$ vs. $4189 \pm 694.1 \mathrm{pg} / \mathrm{mL} ; \quad P<$ $0.01)$ and higher levels of IL-6 levels $(2278 \pm 288.6 \mathrm{pg} /$ $\mathrm{mL}$ vs. $1155 \pm 244.2 \mathrm{pg} / \mathrm{mL} ; P<0.05$ ) (Fig. $4 \mathrm{~b}$ ) in tumor homogenate from $\mathrm{Fgl2}^{-/-}$mice relative to those in WT mice. Additionally, to analyze immunological features, $\mathrm{T}$ cells were detected in tumor and paracancerous tissue, revealing twice as many Th1 cells and $50 \%$ of Tregs in tumors from $\mathrm{Fgl2}^{-/-}$mice relative to levels observed in WT mice (Fig. 4c). Moreover, the proportion of $\mathrm{CD}^{+}{ }^{+} \mathrm{CD}^{+}{ }^{+} \mathrm{T}$ cells among $\mathrm{CD} 45^{+}$cells increased in tumor and paracancerous tissue from $\mathrm{Fgl2}{ }^{-/-}$mice, accompanied by elevated surface expression of CD107a and production of granzyme B (Fig. 4d), which promoted BNL tumor-cell killing in ex vivo assays (Fig. 4e). Similar to subcutaneous HCC models, we found a higher proportion of mature DCs in tumor and paracancerous tissue in orthotopically transplanted hepatomas in $\mathrm{Fgl2}^{-/-}$mice along with decreased presentation of CD31 on DCs from both tissues and elevated CD83 expression in tumor tissue (Fig. 4f). However, the numbers of MDSC and M2 macrophages in tumor and paracancerous tissue were not altered by Fgl2 knockout (Additional file 1: Figure $S 2 b)$.

sFGL2 inhibits the expression of MHCII, CD40, CD80, CD86, and CD83 and phosphorylation of Akt and p38 in BMDCs in vitro

Given our results showing that sFGL2 blockage leads to DC activation in hepatoma, we then investigated the mechanism associated with sFGL2 abolition of DC activation by culturing immature BMDCs with $4 \mu \mathrm{g} / \mathrm{mL}$ recombinant murine FGL2 for $16 \mathrm{~h}$, followed by stimulation with LPS for $12 \mathrm{~h}$ (Fig. 5a). As shown in Fig. 5, sFGL2 significantly reduced the expression of MHCII, CD40, CD80, CD86, and CD83 (Fig. 5b-f). 


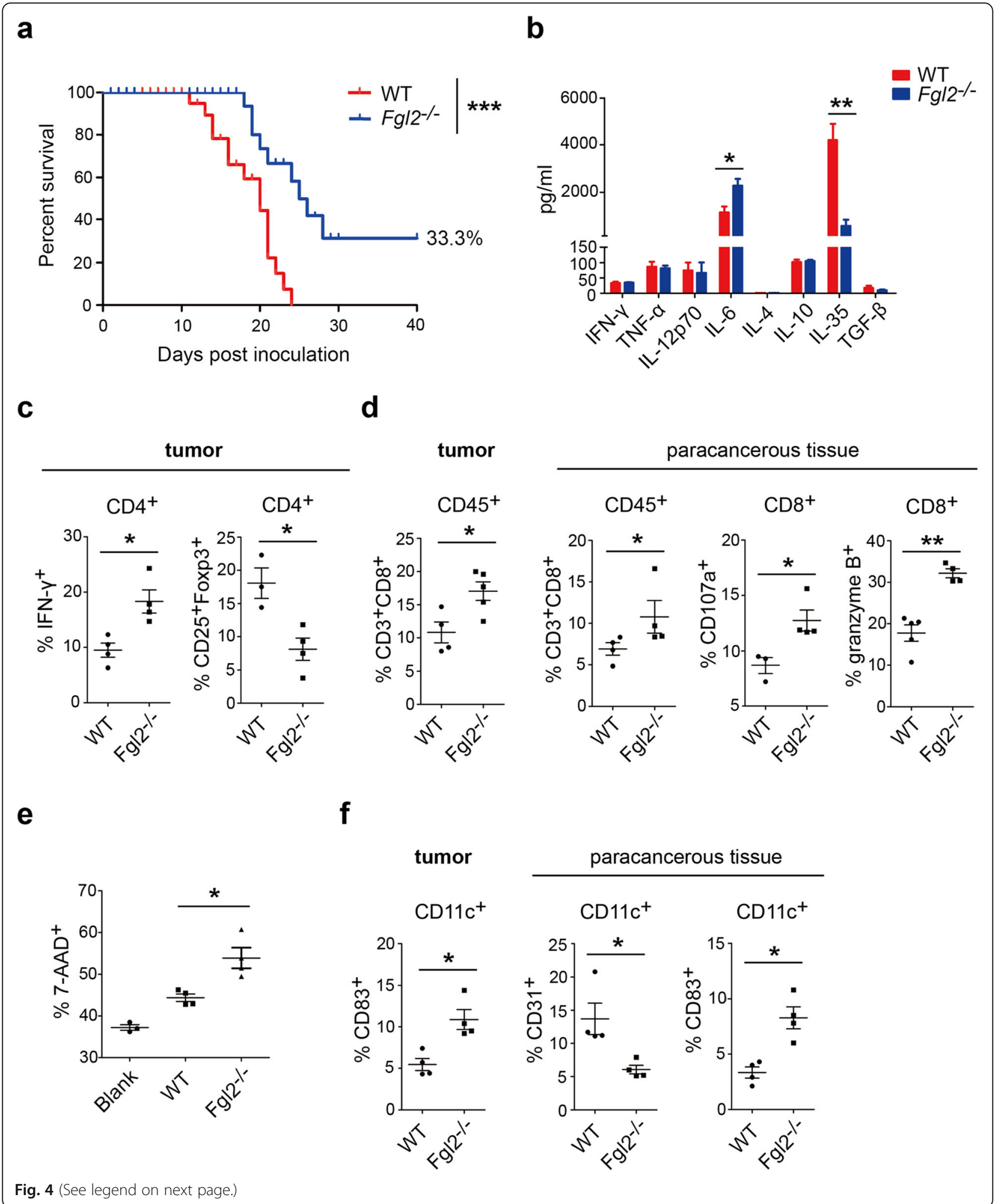


(See figure on previous page.)

Fig. $4 \mathrm{Fgl} 2$ knockout inhibits hepatoma growth and remodels the tumor microenvironment of an orthotopically transplanted HCC model. a BNL cells $\left(1 \times 10^{6}\right)$ were implanted into the left lateral liver lobes of Fg/2 ${ }^{-/-}(n=15)$ or WT $(n=15) \mathrm{BALB} / \mathrm{c}$ mice, and survival curves were generated. Livers were separated at 14-days post-implantation, and animal-survival rates were calculated using the Kaplan-Meier method. ${ }^{* *} P<0.001$ (logrank test) as compared with the negative control group. $\mathbf{b}$ Cytokines in liver homogenate were measured by ELISA or CBA. c CD4 ${ }^{+}$and $\mathbf{d}$ CD8 ${ }^{+} \mathrm{T}$ cells and $\mathbf{f}$ DCs in tumor and paracancerous tissue were analyzed by flow cytometry. e CD8 $8^{+} \mathrm{T}$ cells $\left(1 \times 10^{5}\right)$ from orthotopically transplanted hepatomas were isolated by magnet microbeads and incubated with $1 \times 10^{4} \mathrm{BNL}$ cells for 4 days in 96 -well round-bottomed plates. CD8 ${ }^{+} \mathrm{T}$ cells were mixed with BNL cells at a ratio of 10:1 for $12 \mathrm{~h}$ before measuring the death percentage of BNL cells. Data represent the mean $\pm S E M$. ${ }^{*} P<$ $0.05,{ }^{* *} P<0.01,{ }^{* * *} P<0.001$ (Mann-Whitney $U$ test) as compared with the negative control

We then determined how sFGL2 influenced Akt, p38, and Erk1/2 phosphorylation in DCs. Akt and its downstream effectors, including NF-kB, CREB, and mTOR, function in diverse cellular processes, including cancer progression and insulin metabolism [20, 21]. p38 mitogen-activated protein kinases (MAPKs) are members of the MAPK family, which is critical to the activation of stress and inflammation [22, 23], and Erk1/2 (p44/p42 MAPK) plays an important role in growth and differentiation [24, 25]. In the present study, our results showed that phosphorylation of Akt, NF-kB p65 subunit, CREB, and p38 was significantly attenuated by higher doses of recombinant murine sFGL2 (Fig. 6). At a dose of $2 \mu \mathrm{g} / \mathrm{mL}$ sFGL2, the IOD of p-mTOR was higher than that observed at $0.5 \mu \mathrm{g} / \mathrm{mL}$ and $1 \mu \mathrm{g} / \mathrm{mL}$; however p-Erk1/2 levels were not altered by $\mathrm{sFGL2}$. These data indicated that sFGL2 altered Akt, NF-kB, CREB, and p38 phosphorylation and signaling in DCs to possibly change their phenotype and function.

\section{Discussion}

Blockage of immunosuppressive factors is currently regarded as a primary strategy for cancer immune therapy. Tregs, MDSCs, and TAMs are immunosuppressive cells that abate antitumor immunity via the release of immune-regulatory cytokines and presentation of surface molecules, particularly through immune-checkpoint proteins, such as PD-1 and CTLA-4 [26]. Antibodies targeting immune-checkpoint proteins have been demonstrated as effective at controlling the progression of tumor growth in many Phase III clinical trials [27]; however, clinical efficacy is influenced by tumor type, individual response, targets, and drug administration. Moreover, PD-1 and PD-L1 antibodies exhibit limited clinical efficacy in HCC therapy [28], making it necessary to identify new targets.

The immunosuppressive activity of sFGL2 might represent a potentially important mediator of tumor growth. Previous studies report reductions in tumor growth following Fgl2 knockout in glioma and lung cancer models $[15,16]$. In the present study, we reported for the first time that sFGL2 promoted tumor-microenvironment remodeling and HCC progression, and that hepatoma growth was inhibited following blockage of sFGL2 in both subcutaneously and orthotopically transplanted murine models of hepatoma. In glioma and lung tumor models, levels of MDSCs and M2 macrophages decreased in tumors in Fgl2-knockout groups, suggesting an sFGL2-mediated mechanism promoting tumor growth through increases in these two subsets $[15,16]$. However, in the present study, we found that sFGL2 blockage did not alter the numbers of MDSC and M2 macrophages in HCC models, indicating that sFGL2 might accelerate HCC progression through other pathways.

sFGL2 hinders DC maturation of T cell proliferation in vitro [10]. Therefore, we hypothesized that sFGL2 might promote hepatoma growth by attenuating the number of DCs and T cells, as the main effectors of antitumor immunity. Our results revealed changes in the number, phenotype, and function of DCs and T cells according to sFGL2 status, and that sFGL2 hindered the phosphorylation of mTOR, CREB, Akt, and p38 in BMDCs in vitro. Furthermore, sFGL2 reduced phosphorylated levels of the NF- $\mathrm{kB}$ p65 subunit, which subsequently influenced the expression of inflammatory cytokines and surface molecules in DCs. The effect is mediated by sFGL2 binding to FcyRIIB [11] which downregulates the activation of the factors [29]. However, phosphorylation of these factors was unaltered in $\mathrm{T}$ cells (Additional file 1: Figure S7), indicating that sFGL2 might not directly modulate $\mathrm{T}$ cells. Because changes in Akt and p38 signaling can influence DC maturation and activation [30, 31], we analyzed related surface markers on BMDCs following sFGL2 treatment in vitro, finding that BMDC phenotype was altered by sFGL2 according to decreased levels of MHCII, CD40, CD80, CD86, and CD83 expression. Moreover, in hepatoma-transplanted murine models, sFGL2 blockage promoted MHCII and CD83 expression and downregulated the expression of CD31, which is reportedly an immune-inhibitory marker on the DC surface [32]. These results indicated that sFGL2 blockade promoted DC maturation and inhibited tolerogenic molecule expression on DCs. As the upstream event of adaptive immunity, DC activation can lead to enhanced $\mathrm{T}$ cell activation. Our results showed that DCs from the tumor microenvironment in models 


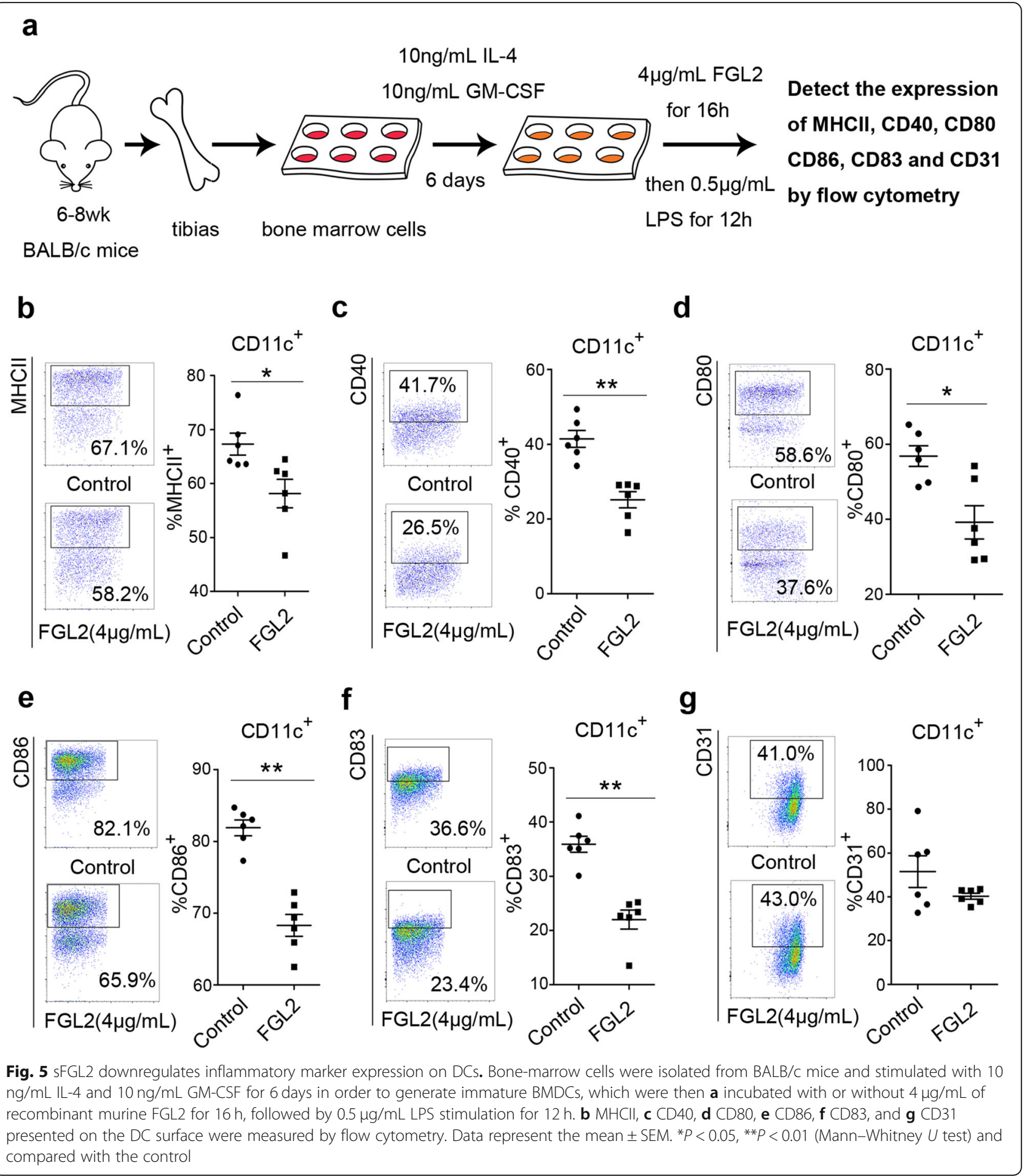

undergoing sFGL2 blockage upregulated T cell proliferation to a greater degree than that observed in controls. Additionally, DCs from mice treated with the sFGL2 antibody induced higher levels of Th1 differentiation from $\mathrm{CD} 4{ }^{+} \mathrm{CD} 25^{-} \mathrm{T}$ cells. These data confirmed a role for sFGL2 in suppressing DC maturation, resulting in inhibited $\mathrm{T}$ cell function.
An increased number of infiltrated $\mathrm{CD}^{+} \mathrm{T}$ cells in the HCC microenvironment produced higher levels of perforin and granzyme B following sFGL2 blockade, with this effect augmented by an elevated number of Th1 cells. Here, we observed fewer Tregs in the tumors of sFGL2-depleted mice, suggesting that a deficiency in tolerogenic DCs might have decreased Treg number. 


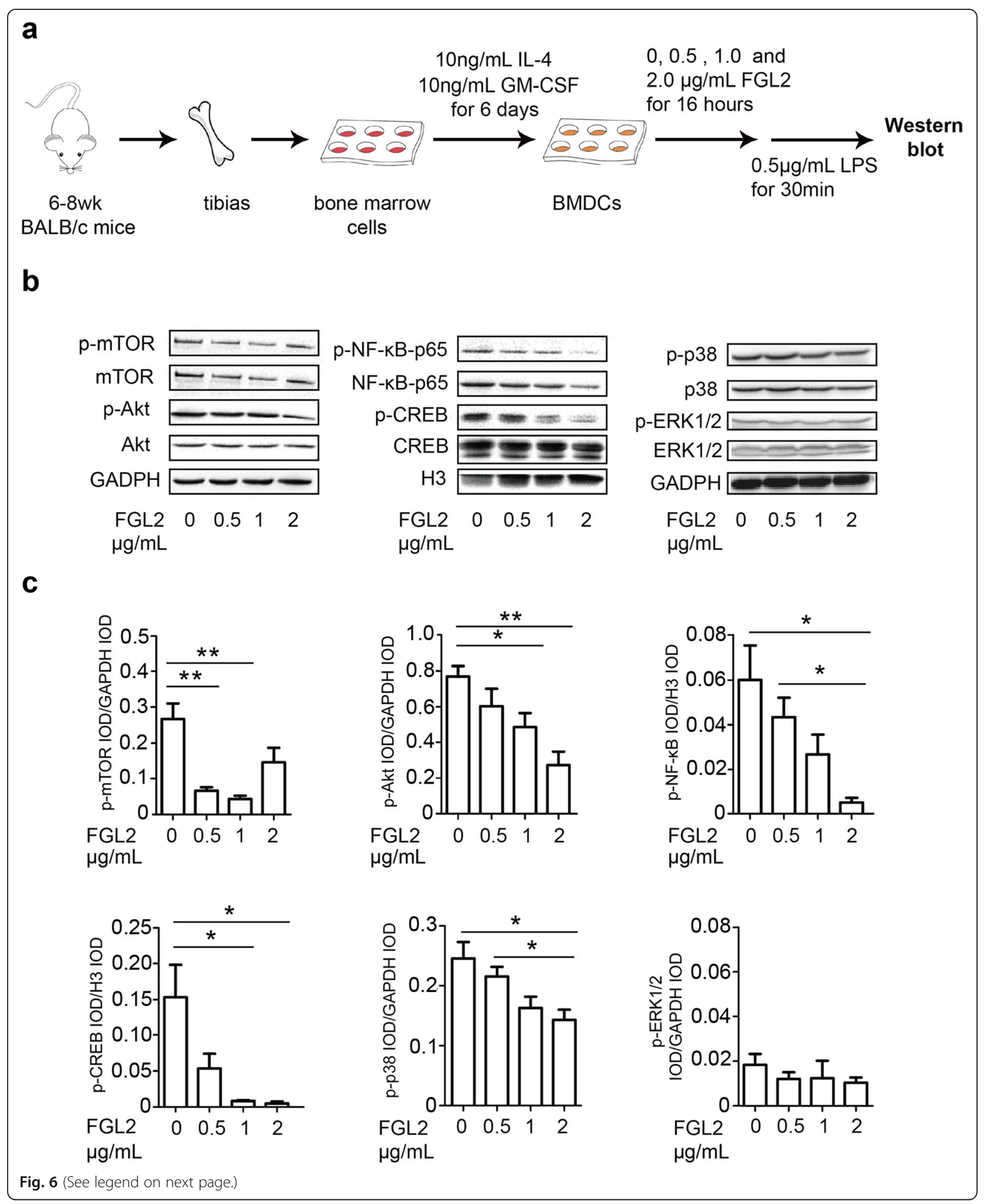


(See figure on previous page.)

Fig. 6 sFGL2 inhibits Akt and p38 phosphorylation and signaling in DCs. Bone-marrow cells were isolated from BALB/c mice and stimulated with $10 \mathrm{ng} / \mathrm{mL} \mathrm{IL-4}$ and $10 \mathrm{ng} / \mathrm{mL}$ GM-CSF for 6 days in order to form immature BMDCs prior to a incubation with different concentrations (0, 0.5, 1.0, and $2.0 \mu \mathrm{g} / \mathrm{mL}$ ) of recombinant murine FGL2 for $16 \mathrm{~h}$, followed by $0.5 \mu \mathrm{g} / \mathrm{mL}$ LPS stimulation for $30 \mathrm{~min}$. Proteins were detected with anti-mTOR, anti-Akt, anti-NF-KB-p65, anti-CREB, anti-p38, anti-ERK1/2, and their respective phosphorylated forms of the antibodies. $\mathbf{b}$ A representative result of three independent experiments and $\mathbf{c}$ the IOD ratio detected protein to that of the internal control are presented as the mean $\pm S E M$. ${ }^{*} P<0.05$,

${ }^{* *} P<0.01$ (Mann-Whitney $U$ test) as compared with each other

However, our data showed that DCs from sFGL2blocked tumors did not inhibit Treg induction from $\mathrm{CD} 4{ }^{+} \mathrm{CD} 25^{-}$cells, indicating that a lower percentage of Tregs in these tumors might not be the results of decreases in the number of DC-induced Tregs. Additionally, we demonstrated that sFGL2 blockage diminished IL-35 levels, which are produced by Tregs. IL-35 plays a vital role of self-tolerance, where IL-35 deficiency promotes autoimmunity in the form of multiple sclerosis, aplastic anemia, allergic rhinitis, and allergic diseases [33]. Moreover, IL-35 promotes tumor growth, with tumor cells overexpressing IL-35 growing faster than controls [34], whereas anti-IL-35 treatment enhances antitumor immunity in vivo [35]. Furthermore, IL-35 in tumor tissue promotes $\mathrm{HCC}$ progression and is associated with HCC recurrence [36]. In the present study, we treated BALB/c mice harboring BNL tumors with intratumoral injection of anti-IL-35 once weekly, with the results showing that IL-35 blockage upregulated the number of Th1 cells and diminished the number of Tregs (Fig. 2g). This suggested that IL-35 might be an indicator capable of assessing the tumor microenvironment based on its promotion of tumor growth; therefore, downregulation of IL-35 levels in the hepatoma microenvironment might promote elevations in the number of Th1 cells and decreased Treg infiltration.

\section{Conclusions}

We found that sFGL2 contributes to HCC development, and that its blockage inhibited hepatoma progression.

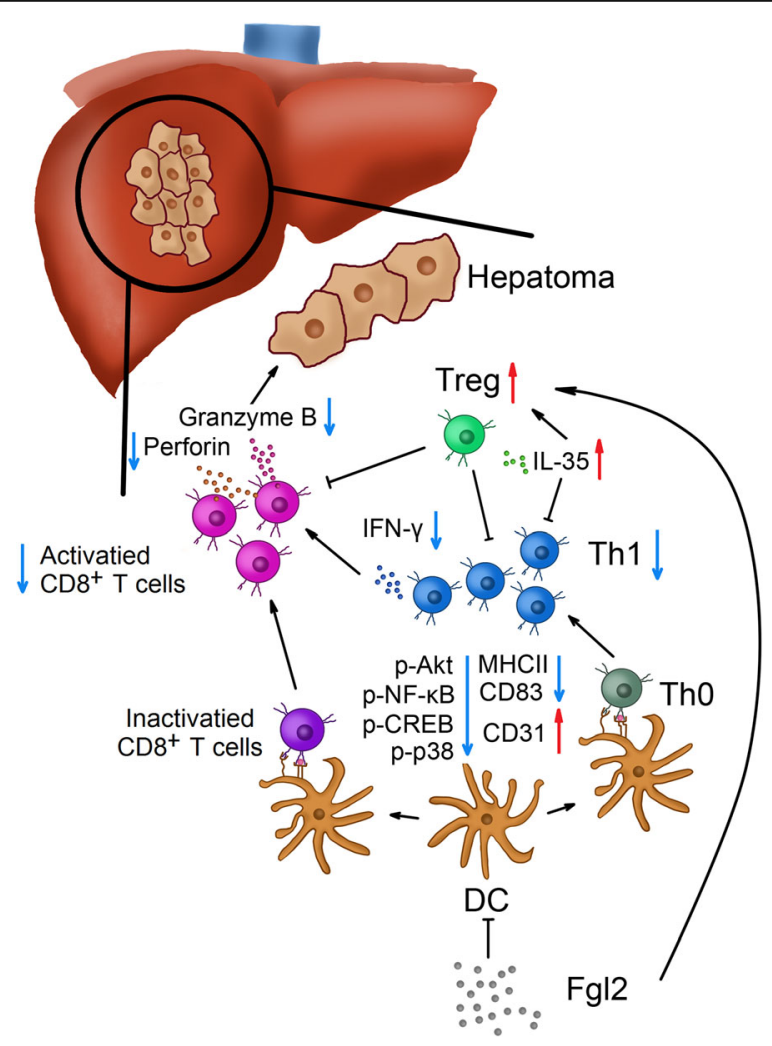

Fig. 7 The potential immunological mechanism of sFGL2 in HCC development. sFGL2 attenuates DC activity by inhibiting Akt signaling and induces DCs into a regulatory state. SFGL2 blockage results in attenuated DC expression of CD83 and MHCIl and increased expression of CD31, which hinders DC-mediated stimulation of $\mathrm{CD} 8^{+} \mathrm{T}$ cells and Th1 cells. Decreased production of granzyme $\mathrm{B}$ and perforin from $\mathrm{CD} 8^{+} \mathrm{T}$ cells exacerbates immunosuppression in the HCC microenvironment. Additionally, the number of Tregs increases along with elevated IL-35 levels. The immunological balance in HCC is thereby disrupted, resulting in dominant immunosuppression and tumor progression 
Additionally, sFGL2 inhibited DC activation by abrogating Akt and p38 signaling resulting in the expression of tolerogenic molecules on DCs and impaired inflammatory phenotypes. Moreover, incomplete activation of DCs by sFGL2 resulting in failed priming of $\mathrm{CD}^{+} \mathrm{T}$ cells might account for tumor growth. Furthermore, increased Tregs in the tumor microenvironment produced higher levels of IL-35, resulting in attenuated levels of $\mathrm{CD}^{+} \mathrm{T}$ cells, Th1 cells, and DCs, which in turn promoted HCC development (Fig. 7). These data support sFGL2 as an important immunomodulatory molecule that might represent a potential therapeutic target for the management of $\mathrm{HCC}$.

\section{Additional file}

Additional file 1: Contains all the supplementary figures and their legends. The titles of the legends are listed below. Figure S1. Fg/2 knockout can diminish significantly sFgl2 level in the hepatoma environment. Figure S2. Fgl2 knockout does not influence the number of MDSCs or M2 macrophages in the hepatoma microenvironment in BALB/C mice. Figure S3. Fgl2 knockout activates CD8 ${ }^{+} \mathrm{T}$ cells and DC maturation in the tumor microenvironment of s.c. transplanted hepatomas in C57BL/6 mice. Figure S4. Anti-FGL2 treatment activates $\mathrm{CD}^{+} \mathrm{T}$ cells and DC maturation in the tumor microenvironment of s.C. transplanted hepatomas in BALB/C mice. Figure S5. Anti-FGL2 treatment activates $\mathrm{CD}^{+} \mathrm{T}$ cells and DC maturation in the tumor microenvironment of s.c. transplanted hepatomas in C57BL/6 mice. Figure S6. Anti-FGL2 treatment promotes DC-mediated proliferation of $\mathrm{T}$ cells in s.c. transplanted hepatomas in BALB/C mice. Figure S7. Akt phosphorylation in T cells is unaltered by sFgl2. (ZIP $2120 \mathrm{~kb}$ )

\section{Abbreviations}

7-AAD: 7-aminoactinomycin D; APC: Allophycocyanin; BCA: Bicinchoninic acid; BMDCs: Bone marrow-derived dendritic cells; CBA: Cytometric beads array; CFSE: Carboxyfluorescein succinimidyl amino ester; CREB: CAMP response element binding protein; CTLA-4: Cytotoxic T-lymphocyteassociated antigen 4; CTLs: Cytotoxic T lymphocytes; DCs: Dendritic cells; DLNs: Draining lymph nodes; ELISA: Enzyme linked immunosorbent assay; ERK: Extracellular signal-regulated kinase; FGL2: Fibrinogen-like protein 2; FITC: Fluorescein isothiocyanate; Foxp3: Forkhead box P3; GMCSF: Granulocyte macrophage-colony stimulating factor; HCC: Hepatocellular carcinoma; IFN: Interferon; IL: Interleukin; IOD: Integrated optical density; LPS: Lipopolysaccharide; MACS: Magnetic cell isolation and cell separation; MAPK: Mitogen-activated protein kinase; MDSCs: Myeloid-derived suppressor cells; MHCII: Major histocompatibility complex II; mTOR: Mechanistic target of rapamycin; NF-kB: Nuclear factor-kappaB; NK: Natural killer; PD1: Programmed cell death 1; PD-L1: Programmed cell death-ligand 1; PE: Phycoerythrin; PerCP: Peridinin chlorophyll; PMA: Phorbol-12-myristate-13acetate; SDS-PAGE: Sodium dodecyl sulfate polyacrylamide gel electrophoresis; sFGL2: Soluble fibrinogen-like protein 2; TAM: Tumorassociated macrophages; TBST: Tris-buffered saline with Tween-20; TGF: Transforming growth factor; Th1: Type $1 \mathrm{~T}$ helper cells; Th2: Type 2T helper cells; TNF: Tumor necrosis factor; Tregs: Regulatory T cells; WT: Widetype

\section{Acknowledgments}

Not applicable.

\section{Authors' contributions}

Conceptualization: QN, DX, XL. Methodology: MY, DX, ZZ. Software: MY, MW, WL. Validation: ZZ, JC, MX. Formal analysis: MY, ZZ, JC. Resources, Investigation and Data Curation: MY, ZZ, MX. Writing - original draft preparation: MY. Writing - review and editing: QN, DX, M-FY, XW.
Visualization and Supervision: JH, DX. Project administration and Funding acquisition: QN. All authors read and approved the final manuscript.

\section{Funding}

This work was supported by National Natural Science Foundation of China (NSFC81571989) and the National Major Science and Technology Special Project on Major New Drug Innovation (2018ZX09733001-002-006).

\section{Availability of data and materials}

All data in the study are included in the published article or the supplement files.

\section{Ethics approval and consent to participate}

All the protocols of animal experiments were in accordance with the Guide for the Care and Use of Laboratory Animals approved by Huazhong University of Science and Technology.

Consent for publication

All authors consent for publication.

\section{Competing interests}

The authors declare that they have no competing interests.

\section{Author details}

${ }^{1}$ Institute of Infectious Disease, Tongji Hospital of Tongji Medical College, Huazhong University of Science and Technology, Wuhan 430030, China.

${ }^{2}$ Department of Infectious Disease, Tongji Hospital of Tongji Medical College, Huazhong University of Science and Technology, Wuhan 430030, China. ${ }^{3}$ Department of Medicine, the University of Hong Kong, Queen Mary Hospital, Hong Kong, China. ${ }^{4}$ Department of Pediatrics, Tongji Hospital of Tongji Medical College, Huazhong University of Science and Technology, Wuhan, China.

Received: 20 February 2019 Accepted: 15 July 2019

Published online: 13 August 2019

\section{References}

1. Torre LA, Bray F, Siegel RL, et al. Global cancer statistics, 2012. CA Cancer J Clin. 2015;65:87-108.

2. Leonardi GC, Candido S. Cervello, et al. the tumor microenvironment in hepatocellular carcinoma (review). Int J Oncol. 2012;40:1733-47.

3. Eggert T, Greten TF. Tumor regulation of the tissue environment in the liver. Pharmacol Ther. 2017;173:47-57.

4. Yi Y, He HW, Wang JX, et al. The functional impairment of HCC-infiltrating gammadelta $T$ cells, partially mediated by regulatory $T$ cells in a TGF betaand IL-10-dependent manner. J Hepatol. 2013;58:977-83.

5. Wu K, Ding J, Chen C, et al. Hepatic transforming growth factor beta gives rise to tumor-initiating cells and promotes liver cancer development. Hepatology. 2012;56:2255-67.

6. Brower V. Checkpoint blockade immunotherapy for cancer comes of age. J Natl Cancer Inst. 2015;107:2-4.

7. Greten TF, Sangro B. Targets for immunotherapy of liver cancer. J Hepatol. 2017. https://doi.org/10.1016/j.jhep.2017.09.007.

8. Hato T, Goyal L, Greten TF, et al. Immune checkpoint blockade in hepatocellular carcinoma: current progress and future directions. Hepatology. 2014;60:1776-82.

9. Hu J, Yan J, Rao G, et al. The duality of Fgl2 — secreted immune checkpoint regulator versus membrane-associated procoagulant: therapeutic potential and implications. Int Rev Immunol. 2014:35:325-39.

10. Chan CW, Kay LS, Khadaroo RG, et al. Soluble fibrinogen-like protein 2/ fibroleukin exhibits immunosuppressive properties: suppressing T cell proliferation and inhibiting maturation of bone marrow-derived dendritic cells. J Immunol. 2003;170:4036-44

11. Liu H, Shalev I, Manuel J, et al. The FGL2-FcgammaRIIB pathway: a novel mechanism leading to immunosuppression. Eur J Immunol. 2008:38:3114-26.

12. Shalev I, Liu H, Koscik C, et al. Targeted deletion of fgl2 leads to impaired regulatory $T$ cell activity and development of autoimmune glomerulonephritis. J Immunol. 2008;180:249-60. 
13. Bartczak A, Zhang J, Adeyi O, et al. Overexpression of fibrinogen-like protein 2 protects against T cell-induced colitis. World J Gastroenterol. 2017;23:2673-84.

14. Shalev I, Wong KM, Foerster $\mathrm{K}$, et al. The novel $\mathrm{CD} 4^{+} \mathrm{CD} 25^{+}$regulatory $\mathrm{T}$ cell effector molecule fibrinogen-like protein 2 contributes to the outcome of murine fulminant viral hepatitis. Hepatology. 2009;49:387-97.

15. Yan J, Kong LY, Hu J, et al. FGL2 as a multimodality regulator of tumormediated immune suppression and therapeutic target in gliomas. J Natl Cancer Inst. 2015;107. https://doi.org/10.1093/jnci/djv137.

16. Zhu Y, Zhang L, Zha H, et al. Stroma-derived fibrinogen-like protein 2 activates cancer-associated fibroblasts to promote tumor growth in lung cancer. Int J Biol Sci. 2017;13:804-14.

17. Van Tong H, Van Ba N, Hoan NX, et al. Soluble fibrinogen-like protein 2 levels in patients with hepatitis B virus-related liver diseases. BMC Infect Dis. 2018;18:553.

18. Sun $Y, X i$ D, Ding W, et al. Soluble FGL2, a novel effector molecule of activated hepatic stellate cells, regulates T-cell function in cirrhotic patients with hepatocellular carcinoma. Hepatol Int. 2014;8:567-75.

19. Liu H, Yang PS, Zhu T, et al. Characterization of fibrinogen-like protein 2 (FGL2): monomeric FGL2 has enhanced immunosuppressive activity in comparison to oligomeric FGL2. Int J Biochem Cell Biol. 2013;45:408-18.

20. Manning BD, Cantley LC. AKT/PKB signaling: navigating downstream. Cell. 2007;129:1261-74.

21. Du K, Montminy M. CREB is a regulatory target for the protein kinase Akt/ PKB. J Biol Chem. 1998;273:32377-9.

22. Coulthard $L R$, White $D E$, Jones $D L$, et al. p38(MAPK): stress responses from molecular mechanisms to therapeutics. Trends Mol Med. 2009;15:369-79.

23. Zarubin T, Han J. Activation and signaling of the p38 MAP kinase pathway. Cell Res. 2005;15:11-8

24. Kim EK, Choi EJ. Pathological roles of MAPK signaling pathways in human diseases. Biochim Biophys Acta. 1802;2010:396-405.

25. Rubinfeld $H$, Seger $R$. The ERK cascade as a prototype of MAPK signaling pathways. Methods Mol Biol. 2004;250:1-28

26. Palucka AK, Coussens LM. The basis of oncoimmunology. Cell. 2016:164:1233-47.

27. Park J, Kwon M, Shin EC. Immune checkpoint inhibitors for cancer treatment. Arch Pharm Res. 2016;39:1577-87.

28. Kudo M. Immune checkpoint inhibition in hepatocellular carcinoma: basics and ongoing clinical trials. Oncology. 2017;92:50-62.

29. Nimmerjahn F, Jeffrey VR. Fcy receptors as regulators of immune responses. Nat Rev Immunol. 2008;8:34-47.

30. Ardeshna KM, Pizzey AR, Devereux S, et al. The PI3 kinase, p38 SAP kinase, and NF-kappaB signal transduction pathways are involved in the survival and maturation of lipopolysaccharide-stimulated human monocyte-derived dendritic cells. Blood. 2000;96:1039-46.

31. Park D, Lapteva N, Seethammagari $M$, et al. An essential role for Akt1 in dendritic cell function and tumor immunotherapy. Nat Biotechnol. 2006;24: 1581-90.

32. Clement M, Fornasa G, Guedj K, et al. CD31 is a key co-inhibitory receptor in the development of immunogenic dendritic cells. Proc Natl Acad Sci U S A. 2014;111:E1101-10.

33. Teymouri M, Pirro M, Fallarino F, et al. IL-35, a hallmark of immuneregulation in cancer progression, chronic infections and inflammatory diseases. Int J Cancer. 2018;143:2105-15.

34. Wang Z, Liu JQ, Liu Z, et al. Tumor-derived IL-35 promotes tumor growth by enhancing myeloid cell accumulation and angiogenesis. J Immunol. 2013;190:2415-23.

35. Turnis ME, Sawant DV, Szymczak-Workman AL, et al. Interleukin-35 limits anti-tumor immunity. Immunity. 2016;44:316-29.

36. Fu YP, Yi Y, Cai XY, et al. Overexpression of interleukin-35 associates with hepatocellular carcinoma aggressiveness and recurrence after curative resection. Br J Cancer. 2016;114:767-76.

\section{Publisher's note}

Springer Nature remains neutral with regard to jurisdictional claims in published maps and institutional affiliations.

\section{Ready to submit your research? Choose BMC and benefit from:}

- fast, convenient online submission

- thorough peer review by experienced researchers in your field

- rapid publication on acceptance

- support for research data, including large and complex data types

- gold Open Access which fosters wider collaboration and increased citations

- maximum visibility for your research: over $100 \mathrm{M}$ website views per year

At BMC, research is always in progress.

Learn more biomedcentral.com/submissions 